\title{
Study on the Thoughts of Teaching Reform on Modern Chinese Literature
}

\author{
Ying Wang ${ }^{1}$ \\ ${ }^{1}$ Yulin University, Yulin, Shanxi, 719000 \\ hunter2011@foxmail.com
}

Keywords: Modern Literature, Teaching Reform

\begin{abstract}
As a compulsory basic course of Chinese language and literature, in the present higher education, the teaching of Modern Chinese Literature faces many unfavorable factors. Various difficulties make the Modern Chinese Literature teaching need constantly updated teaching ideas, to change the traditional teaching methods, emphasis on passing humanistic spirit, strengthen the cultivation of students' comprehensive quality. As a teacher, we should continue to try new ways to make modern literature course more attractive, and try to play their own role.
\end{abstract}

\section{Introduction}

Modern Chinese Literature is a compulsory basic course in University Chinese Language and Literature, occupies an important position in Chinese Specialty discipline. But with the social and economic development in higher education, the discipline gradually re Polytechnic, light humanities, once popular Chinese professional appeal waning, teaching faces many unfavorable factors. Modern Chinese Literature course, the position gradually marginalized, class repeated compression, a single teaching mode, students' interest is not high, the difficulties with making the Modern Chinese Literature Teaching is facing a severe test. To arouse students' enthusiasm for learning in this course, we must continue to update teaching concepts, looking for effective teaching approaches and methods.

\section{Pay Attention to Transfer Humanistic Spirit}

Humanistic spirit is a universal human self-care, the performance of human dignity, values, maintenance of fate, pursue and concern for human spiritual and cultural legacy of the various phenomena of highly valued, ideal for a comprehensive development of personality recognition and shaping. Humanistic spirit is not only a major spiritual content, but also affects the material civilization. It constitutes a nation, a region the core of cultural identity; is a measure of a nation, an important measure of the degree of civilization of the region. Commodity current economic times, the social climate instant success, because the students

Social atmosphere and environment impact of one-child families, more self-centered, lack of

Traditional culture understanding needs love. Therefore, an urgent need for them to Humane Spirit is much important. Literature contains the human love of nature, of life, of the ideals and vision of the future and the pursuit of literature course in culture, portrays aspects of shoulder important mission. From the height should be "human" building to locate the Modern Literature Teaching.

Modern Chinese Literature is an important part of Chinese literature, in three decades of development history of modern literature, resulting in a large number of famous writers, literary theorist and critic. Modern literature contains a complete set of humanistic value system stable, can be said that the crystallization of modern life experience. It contains a wealth of life experience, social experience, emotional experience, artistic experience. Dig in modern literature rich cultural implication of spiritual resources, to establish a contemporary college student lofty life of faith, and establish a new code of ethics, to enhance the humane quality, creating modern all-round development has far-reaching significance. Talk about the content, it should put the history of modern literary life experiences that good writers to convey to young students. Lu Xun, Ba Jin, Lao 
She and other modern writer pursuit of ideals and care Reflections on the country, the fate of the nation, so that modern literature is full of glorious humanistic spirit, shining writer's charisma and humanity shine. In teaching, to highlight the human spirit, the patriotic enthusiasm of students, social responsibility and historical mission, to form a good ideological quality and perfect will of character.

\section{Strengthen the overall quality of training}

Many students do not attach importance to the study of modern literature, is that "literature useless." In the Modern Chinese Literature teaching process, students should be corrected arts professional bias, changing students 'learning psychology and study habits, arouse students' love of literature, and to strengthen the overall quality of their own culture in the learning process.

As in the teaching of modern literature courses, outstanding writers insights on life, attitudes, personality accomplishment, inspire students to improve their capabilities, improve independent strong personality. Training students' ability to think independently and emphasize either the only books, not only on the only solid truth-seeking spirit. By comparing learn to make three-dimensional knowledge, thinking diversification, this course hold a research attitude. Use of effective assessment and testing methods, students innovative ability, written assignments students can focus reflects the flexible use of the knowledge and writing ability level; lecture notes can be seen that the ability to understand students' general ability and shorthand skills; Classroom questioning, class discussion can fully reflect the performance of the students 'basic skills and verbal skills; extracurricular reading notes can effectively reflect the degree of self-learning ability of students to read books; exam test scores to reflect the students' ability to master and apply modern knowledge of literature and rapid response, logical thinking and problem solving skills. In their spare time, they can also organize work seminars, poetry readings, rehearsals drama performances, which can guide the students more contact angle of literary and artistic works, to fully appreciate the artistic charm of literary works, increase participation and practical, real education "people-oriented", a comprehensive overall quality of training of students.

Modern Literature Teaching itself is not a tool, practical employment of the road, we can not become a student of modern literature teaching direct employment of reality, but we can allow students to learn because in modern literature in the formation of knowledge, literacy and the ability to walk on into employment more of a hope, a more confident, more of a success.

\section{Change the Traditional Teaching Mode}

Traditional teaching is teacher-centered, students in a passive position. Teachers 'chalk and talk', students listen to the hearing, the classroom is not obvious. Therefore, teachers must pay attention to classroom interaction, pay attention to the dominant position of the students in the teaching activities, and actively explore effective, lively, lively classroom atmosphere, efforts to improve teaching effectiveness.

The so-called interactive teaching refers to teachers and students between the two sides is an equality body, independent spirit as individuals, teachers are no longer the knowledge and ability to speak, students are no longer the knowledge and ability to accept and transformation objects, both teachers and students in the teaching process, to the language, thought and emotion, can be carried out substantive communication and understanding, in order to achieve mutual respect and dialogue, mutual exchanges, mutual recognition.

Currently more popular interactive teaching mode, there are question-teaching, that teachers do not instill answer directly to the students, but set some highly controversial issues, inspire students to express their views, to enhance students' understanding of knowledge and use, as well as let Students took to the podium of the way, so you can change the learning process inert, prompting the students themselves to think, to obtain information. This helps students to exercise oral communication skills, the ability to logical thinking ability, oral interpretation problem. In addition, teachers can also e-mail, chat, paste it in different ways, etc., and students online communication, 
discuss learning method works, exchange of knowledge on certain issues, so as to compensate for the limited classroom communication deficiencies.

\section{Rational Use of Multimedia Teaching}

Optimization of teaching methods, rational use of audio-visual materials and other multimedia tools, can strengthen the image of modern literature teaching, fun, active classroom atmosphere to stimulate student interest in learning. Slide important adjunct teaching, it makes teachers out of the constraints of chalk, teaching convey information more accurate and clearer. It can be a lot of content, such as poetry or quotations appear on the screen, allowing students to accurately understand about teaching content. Landscaping courseware, try doing illustrations, it can also be appropriate to play poetry, prose recitation audio or according to modern film adaptation of literary classics, which is bound to have a positive effect of classroom teaching. However, when using slides, teachers are often too busy to pay attention to the presence of students in mind the contents of the slide, while ignoring the old problem of teachers corresponding content analysis. Beginning in teaching, teachers should clearly explain to the students the characteristics of teaching slide shows slide is only used to assist learning, the real focus is still on the slide content analysis and understanding.

\section{Conclusion}

In short, the Modern Chinese Literature Teaching is facing difficulties and changes and all of those need to be constantly explored, the goal of our efforts is how to make a modern literature class nature of literature more fit, more attractive, and to maximize the effect of their own.

\section{References}

[1] Y. Wang. Modernization Of Chinese Literature Research. Beijing: Peking University Press, 1996.

[2] WangXiao M. History Of Chinese Literature Theory. Shanghai: Oriental Publishing Center, 1998.

[3] Wen-Ru M. Thoughts On Modern And Contemporary Literature Teaching Reform of Basic Course. China University Teaching. 2004 (02)

[4] Chen Ying. Modern And Contemporary Chinese Literature Teaching Reform And Exploration [J]. Education. 2006 (10)

[5] Tao-De Z. The Textual Necessity And Construction Of Road Modern Chinese Literature Curriculum Reform In Universities In Heilongjiang Research Towards. Higher Education. 2007 (07)

[6] Wang Zhuang. College Chinese Professional Modern Literature Course Teaching Reform. Technology Information, 2009 (30) 